-REVIEW ARTICLE

Volume 11 Issue 12019

DOI: 10.21315/eimj2019.11.1.1

ARTICLE INFO

Submitted: 11-11-2018

Accepted: 24-01-2019

Online: 29-03-2019

\section{Flipped Classroom Teaching Modality: Key Concepts and Practice Endorsements}

\author{
Kamran Sattar', Ahsan Sethi' ${ }^{2}$, Ashfaq Akram³, Tauseef Ahmad ${ }^{3}$, \\ Jennesse John³, Muhamad Saiful Bahri Yusoff' \\ ${ }^{1}$ Department of Medical Education, School of Medical Sciences, \\ Universiti Sains Malaysia, Kelantan, MALAYSIA \\ ${ }^{2}$ Institute of Health Professions Education $\mathcal{E}$ Research, Khyber Medical \\ University, PAKISTAN \\ ${ }^{3}$ Department of Medical Education, College of Medicine, King Saud \\ University, SAUDI ARABIA
}

To cite this article: Sattar K, Sethi A, Akram A, Ahmad T, John J, Yusoff MSB. Flipped classroom teaching modality: key concepts and practice endorsements. Education in Medicine Journal. 2019;11(1):1-10. https://doi.org/10.21315/eimj2019.11.1.1

To link to this article: https://doi.org/10.21315/eimj2019.11.1.1

\title{
ABSTRACT
}

The flipped classroom (FC), an innovative teaching and learning pedagogy has grown in medical education since last decade. In FC modality, students learn by means of print, audio or video-based material self-reliantly, before built-in teaching sessions in the classroom to overcome passive learning. In this review, the key concepts, benefits and best practices of the FC in health professions education have been described. The review was carried out using Medline, Scopus, Ovid, and Cochrane. The keywords were "Flipped method, Teaching strategy, Role of the teacher, and Medical students". Flipped is an effective teaching modality which enables learners to be independent. Students do take ownership of what they learn. Tutors are also satisfied with what their learners acquire. The benefits of FC are robust and likely to augment the learning abilities of the students as well as supplementing the learning course content; group events can deliver added benefits too.

Keywords: Flipped classroom, Medical education, Healthcare professions, Teaching, Faculty, Instructional approach, Learning strategy, Medical students, Role of the teacher

CORRESPONDING AUTHOR Dr. Kamran Sattar, MBBS, MMEd, FAcadMEd, Department of Medical Education, School of Medical Sciences, Universiti Sains Malaysia, 16150 Kubang Kerian, Kelantan, Malaysia | Email: drkamransattar@student.usm.my

\section{INTRODUCTION}

The flipped classroom (FC) also called reverse or backward classroom has reaped international consideration in the past few years as an unconventional and innovative teaching and learning approach in medical education (1-7). The recent literature has focussed on the necessity to reconsider traditional teaching approaches which have also been disparaged for not targeting the fundamental skills in the "real world" such as critical, rational, communication and compound rational $(8,9)$. Evidence backs the use of dynamic learning practices such as collaboration in a team and self-reflection that swift students' involvement, thereby improving their learning outcomes and refining enthusiasm and attitudes $(9,10)$. Grounded on this idea of active learning, a fundamental, yet spontaneous instructive model has been established: the FC. 
The interminable advancement of new technology has encroached in teaching and learning. The FC is basically the inverse of the traditional classroom and homework elements (11-13). The obligation for the attainment of knowledge lies with the students (e.g., through videos, and other online resources), whereas the classroom is devoted to student centered activities such as the actual application of the gathered information, its analysis, synthesis and evaluation. Flipping the classroom has given an exclusive diverse system or advent to the teaching arrangement. The Horizon report ranked it as one of the noteworthy teaching and learning modality in education (14). This new approach enthused facts transmission out of the classroom and material integration into the classroom, allowing coaching of learners as an alternative to lecture (15). It allows learners to apply what they have learned rather than only question solving or text knowledge $(16,17)$. In this review, we present the key concepts, benefits and practices of flipped classroom. We also discuss important areas of FC implementation in health professions education.

\section{SEARCH STRATEGY AND SELECTION CRITERIA}

The PubMed was explored for articles available in the English-language. Medical Subject Headings (MeSH) including "flipped classroom, medical students, faculty, teaching and learning, the role of teacher, medical education, healthcare professions" were cross-referenced in the search which was complemented with a tributary manual search of Scopus, Data Citation Index, Cochrane database and Google Scholar. Furthermore, the ancestory searching was carried out by reviewing the references of the articles acquired from the principal search. Each article was critically appraised and synthesised as appropriate based on reporting primary data, validity of the methods used, clarity of the results and reliance on an established tool to measure outcomes. A subset of important, insightful and high-quality studies was included.

\section{DISCUSSION}

\section{Concept of Flipped Method}

Prior to class, key foundational contents are provided to students, which enable them to be engaged at their own pace. This preclass work provides the foundation for inclass learning which could be reinforced through after-class work and exploration (3). Unlike traditional classroom teaching, FC requires the learners to study on their own before the commencement of actual class sessions. There are three platforms for the learning, Pre-Class, In-Class and After-Class (Figure 1). In "Pre-Class", the students learn new concepts through prereading tasks and other online learning resources, such as videos or lectures as an initial step. During "In-Class", they clarify and consolidate the newly learnt concepts by debating with peers and the tutors. This enables them to learn more by working in a collective project with other learners as well as by having discussions with their tutors (16). While in "After-Class", the students reflect on their learning, this improves retention and transfer (18).

In terms of revised Bloom's taxonomy (19), students achieve lower-order cognition (the attainment of information and understanding) self-reliantly before the classroom training and later attain advanced cognition (application, analysis, evaluation and synthesis) in the classroom segment, where the tutors provide a scaffold. Valued face-to-face time with the tutor is marked for higher order cognition such as concerted learning and presentation of knowledge through problem-resolving, case-based scenarios and imitation, with help from peers (20-22).

The FC implicates a learning method in which self-directed learning takes place before the classroom learning. The aim of the FC is a transferal from passive to 


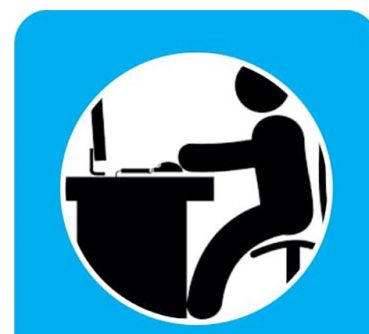

PRE-CLASS

Students concoct to contribute in the class events

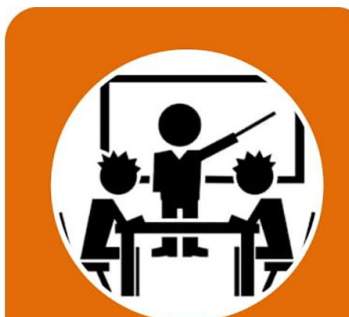

IN-CLASS

Students exercise the solicitation of key concepts

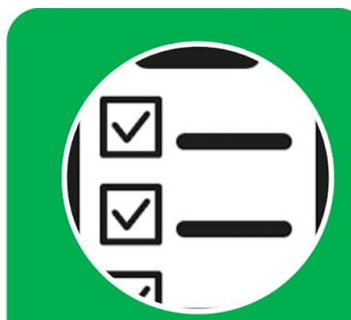

AFTER-CLASS

Students run-through self evaluation for improving their existing knowledge

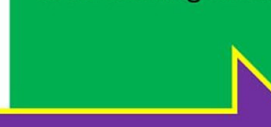

\section{KNOWLEDGE PLATFORMS WITH FLIPPED MODALITY}
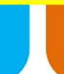

Figure 1: Knowledge platforms within flipped modality.
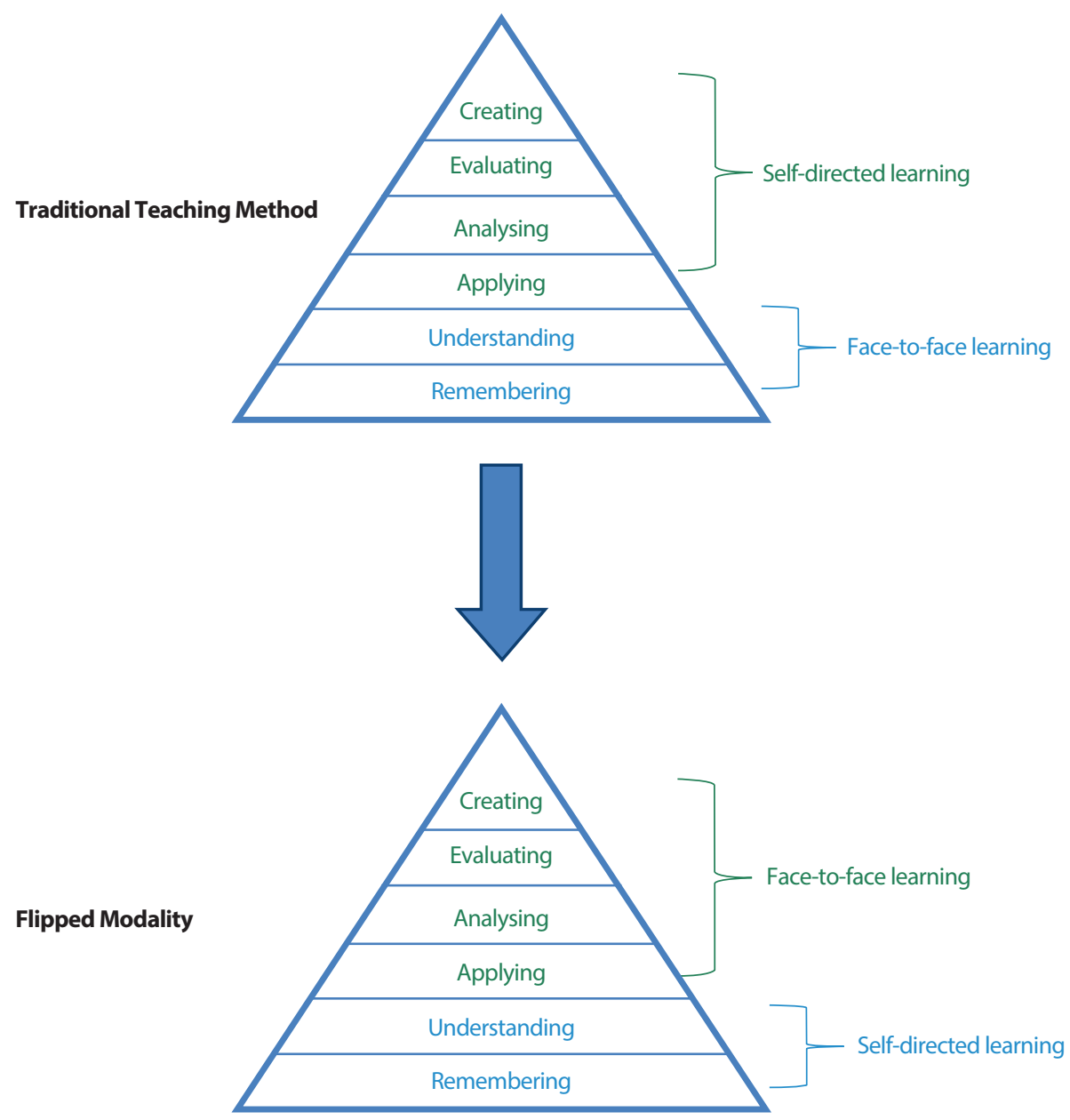

Figure 2: The traditional teaching and the flipped modality in graphic contrast conferring to Bloom's revised taxonomy. 
an augmented learning in the classroom in order to speed up the attainment of more challenging aptitudes such as analysis, blend, and assessment. In terms of Bloom's revised taxonomy (19), this means that students achieve lower-order cognitive progressions (e.g. attainment of knowledge and comprehension) self-reliantly aforementioned to classroom instruction. Moreover, in order to consequently accomplish advanced and complex cognitive learning process (e.g. use of knowledge, analysis, synthesis and evaluation), learners are guided by peers and tutors (Figure 2).

The primary focus of FC is about augmented time for dispensation of new content where learners explore the lecture material, challenge their expertise in smearing the knowledge, and intermingle with one another in hands-on actions. This facilitates learners' engagement in the acquisition of knowledge or skills and they are much more likely to self-regulate their progress and ultimately build self-confidence (22).

\section{Preparing for FC}

Flipped teaching is easy to adopt, but planning requires plenty of tasks to be performed before it is implemented. A commonly practiced way of moving the teaching outside the classroom in a flipped classroom format requires students to watch recorded video lectures prior to attending class (20). Therefore, the tutors need to build their resources such as PowerPoint slide and short videos with a length of 10 to 20 minutes. This stage demands a lot of preparation. It ensures that the important contents are covered in created videos which engage learners actively in and outside the classroom.

Another task is to wisely contemplate the choice of media for the online activities and resources by educators. A common outline of FC can be:

(a) Learners look at a number of lectures of 4 to 10 minutes each (23), (b) Learners evaluate themselves what they have learned through online distributed questions (24),

(c) They are organised into an active workgroup to decipher a problem that some are failing to understand (25),

(d) Tutors commence the discussions where learners work together and put into practice whatever is learned from the resources (26),

(e) They provide feedback reports which help clarify the misunderstanding (27).

FC modality is getting more prevalent because of online instructional materials, making the large group learning effective (28). This offers the learners with instructional content that empowers them to study in their space and exterior of the classroom. In FC model, learners learn by means of print, audio- or video-based material self-reliantly in advance for the teaching session. It is time consuming and demands tutors to be well expert in information technology because the subject materials, in a range of formats like text, images, video, and audio are to be fitted in different learning styles of learners (29). Moreover, having questions in the form of video-based scenario which reflects the understanding of students is a big challenge.

\section{Potential Challenges}

The key impediments to the FC style include earlier work obligations, capacity of learning material, and an overall shortage of time $(1,3)$. The literature is evident of the studies that compare the flipped vs. traditional classroom and it is held that this practice directs future research. Earlier work has reasoned many issues arisen while initiating the FC, yet little work has studied the usefulness of specific practices expanded. In this review, we stress the worth of the learning developments these practices provide. Given that much of the literature mirrors about openings to strengthen the qualities of $\mathrm{FC}$ that would 
ascend from the sustained reflection of the distinct constituents of FC. Evidence promotes that several elements drive in various settings to inspire learners' learning (30). Adopting the FC setting; tutors have to spend time in the class more because group discussion involving the teacher's assistance is merely a part of flipped strategy (31). While watching the lesson videos, students cannot focus on instructional videos $(32,33)$. Consequently, they are unable to raise the questions (34). Most of the time, the videos are quite lengthy. As a result, pre-class activities are time consuming (35).

\section{Benefits to the Learners}

It was observed that FC brought active participation in the students, which was certainly not the case before in traditional teaching methods (36). This is also reflected positively on the student's academic achievement. Because classroom time could be used more amenably, passive learners receive more individual attention while active learners sustain to progress (37).

There is little advantage of working separately with learners in traditional learning method. For example, during a lecture, they are unable to receive a substantial critical assessment or recommendations to progress their performance. Therefore, there is a state of no opportunity to learn or to be mastered in practical life. When measured perceptions of the learners about the prevailing learning experiences associated with FC, the results revealed that the FC delivered more prospects for learners to employ effective interactions with peers and facilitated their own learning (38). The learners get gratification from learning in a FC environment and were able to benefit from watching their lectures in summarised lesson videos (39).

In the digital era, students have more independent access to contents of knowledge than ever before. During the FC once the learners watch online materials, the subsequent discussion permits for a rich prospect to provide a thorough learning and understanding from one's experiences in addition to interaction, active learning, enhancing critical thinking and decision-making (40-43). There is a rising body of substantiation that students can effectively learn the teaching material on their own through various methods (44). FC provides an opportunity for self-paced modality in addition to instructor controlled environment, thus self-directed instruction increases efficiency up to $30 \%$ (45).

Students are well-prepared and contribute actively to the FC teaching as found in many studies $(7,40,46-48)$. They discuss the questions that arose because of direct feedback and availability of study materials forehand. These outcomes are in line with latest studies that have reported encouraging results in student performance and fulfillment by means of FC approach (49). This, in turn, allows the learners to process the information and acquire deep learning. In its essence, however, learning is not a question of acquisition, but active participation of the learner (50). There remains a great deal of students' satisfaction as they take ownership of their learning because they work at their own pace (40). This judgement is similar to the favourable student and faculty reaction lately described by others using the flipped approach $(4,24$, $51,52)$.

Student's motivation heightens, which forms the base for the whole learning process, and can be affected by the strategy of the action. The tutors create a rapport in an open and positive setting which motivates them to contribute to a greater extent in the learning process. Additionally, they also screen their weakness because they find the course as pertinent and connected to their future success. This process makes their educational rough corners soft (53). Also, learners get more inspired and motivated as they find the individuals' implication and value of the material. Regular feedbacks provided by tutors enhance the motivation (54). Similarly, while exploring the impact 
of FC on student learning and satisfaction in Saudi Arabia, it was concluded that FC substitute passive lecturing with active student-centered learning that boosts critical rational and application, together with information preservation (55).

\section{Tutors' Satisfaction}

Tutors are satisfied with the FC concept because it provides avenues for them to become real facilitators of education (41). They are able to guide the learners with explicit detail during discussion. They watch over the learners' activities and give feedback immediately, which augment students' learning. Tutors are able to guide many things for learners outside of the classroom, adding an extra opportunity to deliver information well. In a study in Saudi Arabia, it was stated that FC approach circumvents availability of time and place, enhancing both student and faculty productivity (55). This is deficient in terms of traditional classroom teaching, bringing tension to the tutors' lives. Such tensions lead to detachment, cynicism and weaker sense of identity among tutors (56). This creates a culture of interaction too, and tutors are able to permit for oneto-one and small group assistance. This allows them to exchange and reflect on their understandings about student's needs as well as their level of understanding of the taught content. The greater participation of students is seen as a vital gain of FC. Tutors are able to unite with learners in building study materials which creates a sense of being on board on the part of students. In the FC environment, the teacher is converted into the guide and more of an organiser, aiding and guiding the students in small groups and individuals on the road to education accomplishment in a friendly setting. The advantage of getting students to involve from the start establishes nonthreatening and a safe learning environment for the students for learning through peerpeer and peer-tutor discussions, the learners can try out their ideas, and this also helps them develop confidence in themselves (57, 58).

\section{FC in Medical Education and Healthcare Professions}

There are numerous shortfalls in traditional healthcare professions teachings. It is evident from the literature that the attention span of students in a traditional lecture declines after only 10 minutes and after an average of $15-20$ minutes is lost almost fully. This renders students to have remembered only $20 \%$ of the conducted teaching (59). This necessitates a pressing requirement for FC to be adopted that shall deliver more active knowledge transmission than in traditional lectures. In the medical education and healthcare professions the FC has potential to achieve this effectively by means of online-communicated cases, having the further inherent advantage that the students can learn from their mistakes without endangering patients (60).

The flipped model has already been implemented in several projects in medical education as well as other health professions with very positive outcomes in terms of students' learning enhancement (61-63).

\section{CONCLUSION}

The FC is an exciting student-centered instructional strategy in medical education and health professions education, which had a positive impact on attitudes of students with improved academic performance. Other advantages include enhancing students' decision-making, communication, self-directed learning and critical thinking abilities. However, in spite of the available evidence, backing up the use of the FC, this approach has yet to be implemented widely.

\section{REFERENCES}

1. Persky AM, McLaughlin JE. The flipped classroom - from theory to practice in health professional education. A J Pharm Educ. 2017;81(6):118. https://doi.org/10.5688/ ajpe 816118 
2. Morgan $\mathrm{H}$, McLean $\mathrm{K}$, Chapman $\mathrm{C}$, Fitzgerald J, Yousuf A, Hammoud M. The flipped classroom for medical students. Clin Teach. 2015;12(3):155-60. https://doi.org/ $10.1111 /$ tct. 12328

3. Tan E, Brainard A, Larkin GL. Acceptability of the flipped classroom approach for in-house teaching in emergency medicine. Emerg Med Australia. 2015;27(5):453-9. https://doi.org/10.1111/ 1742-6723.12454

4. Periyakoil VS, Basaviah P. The flipped classroom paradigm for teaching palliative care skills. Virtual Mentor. 2013;15(12):1034-7. https://doi.org/10.1001/ virtualmentor.2013.15.12.medu1-1312

5. Young TP, Baily CJ, Guptill M, Thorp AW, Thomas TL. The flipped classroom: a modality for mixed asynchronous and synchronous learning in a residency program. West J Emerg Med. 2014;15(7):938-44. https://doi.org/10.5811/ westjem.2014.10.23515

6. Prober CG, Khan S. Medical education reimagined: a call to action. Acad Med. 2013;88(10):1407-10. https://doi.org/10. 1097/ACM.0b013e3182a368bd

7. Tune JD, Sturek M, Basile DP. Flipped classroom model improves graduate student performance in cardiovascular, respiratory, and renal physiology. Adv Physiol Educ. 2013;37(4):316-20. https://doi.org/10.1152/ advan.00091.2013

8. O'Flaherty J, Phillips C, Karanicolas S, Snelling C, Winning T. The use of the flipped classroom in higher education: a scoping review. Internet Higher Educ. https://doi.org/10.1016/j. iheduc.2015.02.002.
9. Kamran S, Tauseef A, Mahmoud SK, Mona MS, Gominda GP, Hamza MA. Medical students' perception of the progress test as a quality-controlled assessment tool for improving learning and teaching, at a public sector medical college in Saudi Arabia. J Pak Med Assoc. 2017;67(2):300-4

10. Hurtubise L, Hall E, Sheridan L, Han H. The flipped classroom in medical education: engaging students to build competency. J Med Educ Curricular Dev. 2015;2(1). https://doi.org/10.4137/JMECD.S23895

11. Bergmann J, Sams A. Flip your classroom: reach every student in every class every day. Washington, DC: International Society for Technology in Education; 2012 [cited 17 January 2018]. Available from: https:// www.liceopalmieri.edu.it/wpcontent/ uploads/2016/11/Flip-Your-Classroom.pdf.

12. Gaughan JE. The flipped classroom in world history. History Teach. 2014 [cited 22 February 2018];47(2):221-44. Available from: http://www.societyforhistoryeducation. org/pdfs/F14_Gaughan.pdf

13. Bergmann J, Aaron S. Remixing chemistry class: two Colorado teachers make vodcasts of their lectures to free up class time for hands-on activities. Learning \& Leading with Technology. 2009;36(4):22-7

14. Johnson L, Adams Becker S, Estrada V, Freeman A. NMC horizon report: higher education edition. Austin: The New Media Consortium; 2014 [cited 10 Jan 2018]. Available from: https://www.nmc.org/ publication/nmc-horizon-report-2014higher-education-edition/

15. Crouch $\mathrm{CH}$, Mazur E. Peer instruction: ten years of experience and results. Am J Phys. 2001;69(9):970-7. https://doi.org/ $10.1119 / 1.1374249$ 
16. Moraros J, Islam $\mathrm{A}, \mathrm{Yu} \mathrm{S}$, Banow $\mathrm{R}$, Schindelka B. Flipping for the success: evaluating the effectiveness of a novel teaching approach in a graduate level setting. BMC Med Educ. 2015; 28;15(27). https:// doi.org/10.1186/s12909-015-0317-2

17. Jesurasa A, Mackenzie $\mathrm{K}$, Jordan $\mathrm{H}$, Goyder EC. What factors facilitate the engagement with flipped classrooms used in the preparation for postgraduate medical membership examinations? Adv Med Educ Prac. 2017;8:419-26. https://doi. org/10.2147/AMEP.S132266

18. Harden RM, Jennifer ML, Jean SK, Helen EM. AMEE Medical Education Guide No.7: task based learning: an educational strategy for under graduate postgraduate and continuing medical education, Part 2 . Med Teach. 1996;18(2):91-8. https://doi. org/10.3109/01421599609034140

19. Anderson LA, Krathwohl DR, Bloom BS. A taxonomy for learning, teaching and assessing: a revision of Bloom's taxonomy of educational objectives. New York: Addison Wesley Longman; 2001

20. Abeysekera L, Phillip D. Motivation and cognitive load in the flipped classroom: definition, rationale and a call for research. Higher Education Research \& Development. 2015;34:1-14. https://doi.org/10.1080/0729 4360.2014 .934336

21. Johnson DW, Johnson RT, Smith KA. Cooperative learning returns to college: what evidence is there that it works? Change: The Magazine of Higher Learning. 1998;30:26-35. https://doi.org/ $10.1080 / 00091389809602629$

22. Clark KR. The effects of the flipped model of instruction on student engagement and performance in the secondary mathematics classroom. J Educ Online. 2015;12:91-115.

23. Moffett J. Twelve tips for 'flipping' the classroom. Med Teach. 2015;37(4):331-6. https:/doi.org/ 10.3109/ 0142159X.2014.943710
24. Sharma N, Lau CS, Doherty I, Harbutt D. How we flipped the medical classroom. Med Teach. 2015;37(4):327-30. https://doi.org/1 $0.3109 / 0142159 X .2014 .923821$

25. Kurup V, Hersey D. The changing landscape of anesthesia education: is flipped classroom the answer? Curr Opin Anaesthesiol. 2013;26(6):726-31. https:// doi.org/10.1097/ACO.0000000000000004

26. Mehta NB, Hull AL, Young JB, Stoller JK. Just imagine: new paradigms for medical education. Acad Med. 2013;88(10):141823. https://doi.org/10.1097/ACM.0b013e $3182 \mathrm{a} 36 \mathrm{a} 07$

27. Mok HN. Teaching tip: the flipped classroom. J Inform Syst Educ. 2014;25:711

28. Mason G, Shuman T, Cook K. Comparing the effectiveness of an inverted classroom to a traditional classroom in an upperdivision engineering course. IEEE $\mathrm{T}$ Educ. 2013;56:430-5. https://doi.org/10.1109/ TE.2013.2249066

29. Freeman S, Eddy SL, McDonough M, Michelle KS, Nnadozie O, Hannah J, Mary PW. Active learning increases student performance in science, engineering and mathematics. Proc Nat Acad Sci USA. 2014;111(23):8410-5. https://doi. org/10.1073/pnas.1319030111

30. Crouch $\mathrm{CH}$, Mazur E. Peer instruction: ten years of experience and results. Am J Phys. 2001;69:970-7. https://oi. org/10.1119/1.1374249

31. Chung KL, Foon KH. A critical review of flipped classroom challenges in K-12 education: possible solutions and recommendations for future research. Research and Practice in Technology Enhanced Learning. 2017;12:4. https://doi. org/10.1186/s41039-016-0044-2 
32. Jesurasa, A, Mackenzie K, Jordan H, Goyder EC. What factors facilitate the engagement with flipped classrooms used in the preparation for postgraduate medical membership examinations? Advances in Medical Education and Practice. 2017;8:419-26. https://doi.org/10.2147/ AMEP.S132266

33. Lage MJ, Platt G, Treglia M. Inverting the classroom: a gateway to creating an inclusive learning environment. J Econ Educ. 2000;31(1):30-43. https://doi.org/ $10.1080 / 00220480009596759$

34. Pascarella ET, Terenzini PT. How college affects students. A third decade of research. Journal of College Student Development. 2006 [cited 5 December 2017]; 47:508-20. Available from: https:// edocs.uis.edu/Departments/LIS/Course_ Pages/LIS301/papers/How_college_effects_ students_534-545.pdf.

35. Brian JB, Michael A. Student perceptions of a flipped classroom management course. J Appl Research Higher Educ. 2016;8:316-28. https://doi.org/10.1108/ JARHE-09-2015-0069

36. Kettle M. Flipped physics. Physics Education. 2013;48:593-6.

37. Schultz D, Duffield S, Rasmussen SC, Wageman J. Effects of the flipped classroom model on student performance for advanced placement high school chemistry students. J Chemical Education. 2014;91:1334-9. https://doi.org/10.1021/ed400868x

38. Bhagat KK, Chang CN, Chang CY. The impact of the flipped classroom on mathematics concept learning in high school. Educational Technology and Society. 2016;19(3):134-42. https://www. jstor.org/stable/jeductechsoci.19.3.134

39. Wang YH. Could a mobile assisted learning system support flipped classrooms for classical Chinese learning? J Computer Assisted Learning. 2016;32:91-415. https:// doi.org/10.1111/jcal.12141
40. McLaughlin JE, Roth MT, Glatt DM, Gharkholonarehe N, Davidson CA, Griffin LM, Esserman DA, Mumper RJ. The flipped classroom: a course redesign to foster learning and engagement in a health professions school. Acad Med. 2014;89(2):236-43. https://doi.org/10.1097/ ACM.0000000000000086

41. Persky AM, Pollack GM. Transforming a large-class lecture course to a smallergroup interactive course. Am J Pharm Educ. 2010;74(9):170.

42. McLaughlin JE, Rhoney DH. Comparison of an interactive e-learning preparatory tool and a conventional downloadable handout used within a flipped neurologic pharmacotherapy lecture. Curr Pharm Teach Learn. 2015;7:12-9. https://doi.org/ 10.1016/j.cptl.2014.09.016

43. Clark RE. Reconsidering research on learning from media. Rev Educ Res. 1983;53:445-59. https://doi.org/10.2307/ 1170217

44. Roach T. Student perceptions toward flipped learning: new methods to increase interaction and active learning in economics. Int Rev Econ Educ. 2014;17:74-84. https:// doi.org/10.1016/j.iree.2014.08.003

45. Missildine K, Fountain R, Summers L, Gosselin K. Flipping the classroom to improve student performance and satisfaction. J Nurs Educ. 2013;52(10):5979. https://doi.org/10.3928/01484834-2013 0919-03

46. Moravec M, Williams A, Aguilar-Roca $\mathrm{N}$, O'Dowd DK. Learn before lecture: a strategy that improves learning outcomes in a large introductory biology class. CBE Life Sci Educ. 2010;9(4):473-81. https://doi.org/ 10.1187/cbe.10-04-0063

47. Hashmi NR. Team based learning (TBL) in undergraduate medical education. J Coll Phys Surg Pak. 2014;24(8):553-6. 
48. Van der Vleuten CP, Driessen EW. What would happen to education if we take education evidence seriously? Perspect Med Educ. 2014;3(3):222-32. https://doi. org/10.1007/s40037-014-0129-9

49. Prunuske AJ, Batzli J, Howell E, Miller S. Using online lectures to make time for active learning. Genetics. 2012;192(1):67-72. https://doi.org/10.1534/genetics.112.141754

50. Burnette K, Ramundo M, Stevenson M, Beeson MS. Evaluation of a web based asynchronous pediatric emergency medicine learning tool for residents and medical students. Acad Emerg Med. 2009;16 Suppl 2:S46-50. https://doi.org/10.1111/j.15532712.2009.00598.x

51. Khanova J, Roth MT, Rodgers JE, McLaughlin JE. Student experiences across multiple flipped courses in a single curriculum. Med Educ. 2015;49(10):103848. https://doi.org/10.1111/medu.12807

52. Sethi A, Ajjawi R, McAleer S, Schofield $\mathrm{S}$. Exploring the tensions of being and becoming a medical educator. BMC Med Educ. 2017;17(1):62. https://doi.org/10. 1186/s12909-017-0894-3

53. Edmunds S, Brown G. Effective small group learning: AMEE Guide No. 48. Med Teach. 2010;32(9):715-26. https://doi.org/10.3109/ 0142159X.2010.505454

54. Carpenter SK, Lund TJ, Coffman CR, Armstrong PI, Lamm MH, Reason RD. A classroom study on the relationship between student achievement and retrievalenhanced learning. Educational Psychology Review 2016;28(2):353-75. https://doi. org/10.1007/s10648-015-9311-9

55. Sajid MR, Laheji AF, Abothenain F, Salam Y, AlJayar D, Obeidat A. Can blended learning and the flipped classroom improve student learning and satisfaction in Saudi Arabia? International Journal of Medical Education. 2016;7:281-5. https://doi.org/ 10.5116/ijme. $57 \mathrm{a} 7.83 \mathrm{~d} 4$
56. Mortensen CJ, Nicholson AM. The flipped classroom stimulates greater learning and is a modern 21 st century approach to teaching today's undergraduates. J Anim Sci. 2015;93(7):3722-31. https://doi.org/ 10.2527/jas.2015-9087

57. Howard SW, Scharff DP, Loux TM. Flipping classrooms in a school of public health. Front Public Health. 2017;5:73. https://doi.org/10.3389/fpubh.2017.00073

58. Terri HW, Eric JI, Ingrid L, Vanishree R. Pharmacy students' performance and perceptions in a flipped teaching pilot on cardiac arrhythmias. Am J Pharm Educ. 2014;78(10):185. https://doi.org/10.5688/ ajpe7810185

59. Hartley J, Cameron A. Some observations on the efficiency of lecturing. Educ Rev. 1967;20:30-7. https://doi.org/10.1080/ 0013191670200103

60. Kononowicz AA, Hege I. Virtual patients as a practical realisation of the e-learning idea in medicine. In: Safeeullah S, editor. E-learning: experience and future. Vukovar, Croatia: Intech; 2010. p. 345-70. https://doi. org/10.5772/8803

61. Heiman HL, Uchida T, Adams C, Butter J, Cohen E, Persell SD, Pribaz P, MacGaghie WC, Martin GJ. E-learning and deliberate practice for oral case presentation skills: a randomized trial. Med Teach. 2012;34(12):e820-6. https://doi.org/10.3109 /0142159X.2012.714879

62. Tune JD, Sturek M, Basile DP. Flipped classroom model improves graduate student performance in cardiovascular, respiratory, and renal physiology. Adv Physiol Educ. 2013;37(4):316-20. https://doi.org/10.1152/ advan.00091.2013

63. Street SE, Gilliland KO, McNeil C, Royal $\mathrm{K}$. The flipped classroom improved medical student performance and satisfaction in a pre-clinical physiology course. Med Sci Educ. 2015;25:35-43. https://doi.org/10. 1007/s40670-014-0092-4 